Repartimiento y conflictos en San Pedro Molinos, jurisdicción de Teposcolula, Oaxaca, fines del siglo XVIII Dossier La vigencia del estudio de los repartimientos en época de subdelegados

https://dx.doi.org/10.12795/Temas-Americanistas.2021.i46.04

\title{
REPARTIMIENTO Y CONFLICTOS EN SAN PEDRO MOLINOS, JURISDICCIÓN DE TEPOSCOLULA, OAXACA, FINES DEL SIGLO XVIII DISTRIBUTION AND CONFLICTS IN SAN PEDRO MOLINOS, JURISDICTION OF TEPOSCOLULA, OAXACA, LATE 18TH CENTURY
}

\author{
Huemac Escalona Lüttig \\ Unidad Oaxaca IIH/UNAM \\ ORCID: 0000-0001-6913-737X \\ Edgar Mendoza García \\ CIESAS \\ ORCID: 0000-0003-1365-3011
}

\section{Resumen:}

El distrito de Teposcolula fue uno de los territorios más extensos y poblados de la intendencia de Oaxaca. Su economía y dinámicas sociopolíticas estaban articuladas al repartimiento de mercancías. En 1787 el pueblo de indios San Pedro Molinos inició un litigio contra su alcalde mayor y tenientes por abusos en los repartos. A partir del análisis del pleito, en el que intervinieron también el cacique local y el párroco, se muestra el impacto de la aplicación del artículo 12 de la Ordenanza de intendentes en esta región.

Palabras clave: Teposcolula, repartimiento de mercancías, ordenanza de intendentes

\begin{abstract}
:
The Teposcolula district was one of the largest and most populated territories of the Oaxaca Intendencia. Its economy and socio-political dynamics were linked to the distribution of goods. In 1787 the Indian town of San Pedro de los Molinos initiated a lawsuit against its mayor and lieutenants for abuse in the distribution. From the analysis of the lawsuit, in which the local chief and the parish priest also intervened, the impact of the application of article 12 of the mayors ordinance is shown in this region.
\end{abstract}

Keywords: Teposcolula, distribution of goods, mayors Ordinance 


\section{AMERICANISTAS}

ISSN 1988-7868

\section{Huemac Escalona y Edgar Mendoza \\ Repartimiento y conflictos en San Pedro Molinos, jurisdicción de Teposcolula, Oaxaca, fines del siglo XVIII \\ Dossier La vigencia del estudio de los repartimientos en época de subdelegados}

Desde principios del siglo XXI, la historia global ha sido uno de los principales enfoques teóricos utilizados para analizar las articulaciones de los imperios europeos que se extendieron por distintos continentes. ${ }^{1}$ En este contexto historiográfico se originó y situó la corriente teórica denominada "Nuevas Instituciones Económicas", 2 cuyos estudios se orientaron al análisis de la organización de "economías de alto riesgo". Entre estos, también se incluyó al sistema de repartimiento de mercancías que funcionó en varios territorios de la América española. Sin embargo, tanto los estudios de viejo cuño como los actuales sobre este mecanismo financiero, han generado distintas interpretaciones y debates. En ese sentido, vale la pena considerar las últimas reflexiones sobre la relación entre historia global e historia local, ${ }^{3}$ para comprender de forma más compleja los distintos niveles de escala y sus interacciones.

La historiografía que aborda el mecanismo de distribución de mercancías durante el periodo colonial novohispano se ha dividido en dos grandes bloques. Por un lado, hay historiadores que apuntan, que el repartimiento fue un sistema mercantil de carácter coercitivo que los corregidores y alcaldes mayores impusieron a la población indígena para obtener enormes ganancias, lo que desató inconformidad, reclamos y resistencias por parte de los pueblos. ${ }^{4}$ Por otra parte, hay quienes argumentan que el sistema no fue

\footnotetext{
${ }^{1}$ Bajo dicho enfoque, se han abordado la organización de redes mercantiles, la movilidad de funcionarios, la circulación de información y de objetos por América, Asia y África. Véase: Kenneth Pomeranz y Steven Topik, The World that Trade Created: Society, Culture, and the World Economy, 1400 to the Present. New York: M. E. Sharpe, 2006; Steven Topik, Carlos Marichal y Zephyr Frank (eds), From silver to cocaine. Latin American commodity chains and the building of the world economy, 1500-2000. Durham: Duke University Press, 2006; y Manuel Pérez García y Lucio De Sousa (eds), Global History and New Polycentric Approaches. Europe, Asia and the Americas in a World Network System. Singapore: Palgrave Macmillan, 2018.

${ }^{2}$ Véase Jeremy Baskes, Indians, merchants and markets: a reinterpretation of the "repartimiento" and Spanish-Indian economic relations in colonial Oaxaca, 1750-1821, Stanford (California): Stanford University Press, 2000).

${ }^{3}$ Giovanni Levi, "Microhistoria e Historia Global”, en Historia Crítica, n. ${ }^{\circ} 69$ (2018), pp. 21 - 35.

4 Menegus, Margarita, "La economía indígena y su articulación al mercado en Nueva España. El repartimiento forzoso de mercancías", en Margarita Menegus (Coord.), El repartimiento forzoso en México, Perú y Filipinas, México: Instituto Mora/UNAM, 2000, pp. 9-64; Laura Machuca, "El impacto del repartimiento de mercancías en la provincia de Tehuantepec durante el siglo XVIII: los pueblos de la grana", en Margarita Menegus, Op cit, pp. 120-145; Nancy Farris, La sociedad maya bajo el dominio colonial, México: INAH, 2012; Robert Patch y Beatriz Cáceres, "The Repartimiento and Indigenous People in the Spanish Empire: New Perspectives and Old Realities", en Antonio Escobar y Teresa Rojas (Edits.), Estructuras y formas agrarias en México, del pasado y del presente, México: CIESAS/Secretaría de la Reforma Agraria, 2001, pp. 121-143; Luis Alberto Arrioja Díaz Viruell, "De la prohibición a la persistencia: el repartimiento de mercancías en Villa Alta (Oaxaca), 1786-1834", en Daniela Traffano, Reconociendo al pasado. Miradas Históricas sobre Oaxaca, Oaxaca: CIESAS/UABJO/Carteles Editores,
} 


\section{AMERICANISTAS}

ISSN 1988-7868

\section{Huemac Escalona y Edgar Mendoza \\ Repartimiento y conflictos en San Pedro Molinos, jurisdicción de Teposcolula, Oaxaca, fines del siglo XVIII \\ Dossier La vigencia del estudio de los repartimientos en época de subdelegados}

obligatorio sino que los indios participaron de manera voluntaria en dichos tratos y en el comercio regional porque les era redituable para pagar sus tributos, comprar animales de carga, obtener mercancías hispanas y financiar sus fiestas patronales. ${ }^{5}$ Otros en cambio, tratan de incluir ambas visiones para mostrar las eficiencias o deficiencias del sistema, así como la articulación de circuitos mercantiles locales y regionales. ${ }^{6}$ ¿Por qué se ha llegado a estas interpretaciones tan contrastantes? Quizá la respuesta se encuentra en los mismos documentos de la época que fueron escritos por la propia burocracia que vivió los cambios generados por la Ordenanza de intendentes, y también por las inconformidades que presentaron ciertos sacerdotes y pueblos contra los alcaldes mayores, donde sobresalen opiniones que estuvieron a favor o en contra de la prohibición del reparto de mercancías.

Desde esta última perspectiva, el enfoque y los resultados pueden variar según la región que se aborde, el tipo de población, productos comerciales, presencia de haciendas y cercanía de minas y ciudades. ${ }^{7}$ El análisis crítico de fuentes, ofrece un abanico de

\footnotetext{
2008, pp. 91-129; Carlos Sánchez Silva, "Indios y repartimientos en Oaxaca a principios del siglo XIX”, en Antonio Escobar (Coord.), Indio, Nación y Comunidad en el México del Siglo XIX, México: Centro de Estudios Mexicanos y Centroamericanos/Centro de Investigaciones y Estudios Superiores en Antropología Social, 1993, pp. 105-118; Cristina García Bernal, "La polémica en torno a los repartimientos de comercio a los indios en la América española", en Jean-Pierre Molénata, Minorías y migraciones en la historia. XV Jornadas de Estudios Históricos, Salamanca: Ediciones Universidad de Salamanca, 2004, pp. 151-177; John K. Chance, La conquista de la sierra. Españoles e indígenas de Oaxaca en la época de la Colonia, México, Instituto Oaxaqueño de las Culturas/Fondo Estatal para la Cultura y las Artes/CIESAS, 1998; Francisco Jiménez Abollado, "La querella contra los repartimientos forzosos de mercancías: levantamiento y revuelta en el sureste novohispano,1668-1671", en Boletín del Archivo General de la Nación, 6a época: 10, México, ( 2005), pp. 110-129.

5 Baskes, Indians, merchants and markets, op cit; Arij Ouweenel, " El gobernador de indios, el repartimiento de comercios y la caja de comunidad en los pueblos de indios del México central (siglo XVIII), en Menegus, Margarita (Coord.), Op cit, pp. 65-97; Horst Pietschmann, "El comercio de repartimientos de los alcaldes mayores y corregidores en la región de Puebla-Tlaxcala en el siglo XVIII", en Estudios sobre política indigenista española en América, Valladolid, Universidad de Valladolid, 1977, pp. 147-153.

6 Barbro Dhalgren, La grana cochinilla, México: UNAM, 1990, pp. 27-29; Rodolfo Pastor, "El repartimiento de mercancías y los alcaldes mayores novohispanos: un sistema de explotación, de sus orígenes a la crisis de 1810", en Woodrow Borah, El gobierno provincial de la Nueva España, 1570-1787, México: UNAM, 1985, pp. 201-236; Brian Hamnett, Política y comercio en el sur de México, 1750-1821, Oaxaca, UABJO/El Colegio de Michoacán/El Colegio de San Luis, 2013; Huemac Escalona Rojo profundo: grana cochinilla y conflicto en la jurisdicción de Nexapa, nueva España, siglo XVIII, Sevilla, Universidad Pablo de Olavide, tesis doctoral, 2015, pp. 158-175, y Carmagnani, Marcello. "Una institución económica colonial: repartimiento de mercancías y libertad de comercio", en Historia Mexicana, vol. 54: 1, (2004), pp. 249-262.

7 Menegus, "La economía indígena”, op cit.
} 


\section{AMERICANISTAS}

ISSN 1988-7868

Huemac Escalona y Edgar Mendoza

Repartimiento y conflictos en San Pedro Molinos, jurisdicción de Teposcolula, Oaxaca, fines del siglo XVIII Dossier La vigencia del estudio de los repartimientos en época de subdelegados

opiniones contrastantes donde se perciben los intereses económicos de funcionarios reales, mercaderes, sacerdotes, caciques y pueblos involucrados. Asimismo, se conocen los motivos de conflictos, acuerdos y negociaciones que se suscitaron entre los distintos actores sociales que participaron directa o indirectamente en dicho sistema mercantil. Tampoco se puede dejar de lado la legislación y las coyunturas políticas y económicas que marcaron cambios y dieron lugar a múltiples respuestas. Tal fue el caso de la Ordenanza de Intendentes de 1786, que prohibió a los alcaldes mayores el repartimiento de mercancías y de dinero a la población de sus jurisdicciones a cambio de sus productos textiles, agrícolas y ganaderos. Se sabe que en algunos lugares, rápidamente se acataron estas disposiciones, mientras que en otras regiones el mecanismo se mantuvo hasta principios del siglo XIX. ${ }^{8}$

Carlos Sánchez Silva realiza una aproximación a lo ocurrido en la Intendencia de Oaxaca con los repartimientos en las primeras décadas del siglo XIX. Este autor brinda un panorama sobre los conflictos generados en ese periodo en distintas jurisdicciones oaxaqueñas y analiza el papel desempeñado por los diferentes actores sociales en un contexto político convulso. Además, afirma que el sistema de repartimiento continuó operando a gran escala en varias zonas de la intendencia. Como muestra, presenta una relación de protestas en contra de dicho sistema, ocurridas entre 1788 y 1818 . No obstante indica que las comunidades indígenas "mostraron una gran perspicacia en cuanto a la existencia de la prohibición", como lo demostraron sus actos y argumentos tanto legales y como aquellos situados al margen de las normativas. ${ }^{9}$

Consideramos que los años inmediatos a la aplicación de la ordenanza de intendentes de 1786, son cruciales para dilucidar las consecuencias de la nueva normativa. Según Sánchez Silva, entre 1787 y 1818 tuvieron lugar 32 conflictos por los repartimientos, la mitad de ellos en los primeros diez años. Desde la última década del siglo XVIII hasta las primeras del siglo XIX, doce motines ocurrieron en la jurisdicción de Villa Alta, una de las más pobladas y valoradas de la intendencia de Oaxaca, mientras

\footnotetext{
8 Los siguientes autores abordan la continuidad de los repartimientos a pesar de su prohibición en 1786: Arrioja, "De la prohibición", op cit; Sánchez Silva, "Indios y repartimientos" op cti,; y Rodolfo Pastor, Campesinos y reformas, la mixteca: 1700-1856, México: El Colegio de México, 1987.

9 Sanchez Silva, "Indios y repartimientos", op cit, p. 107.
} 


\section{AMERICANISTAS}

\section{ISSN 1988-7868}

Huemac Escalona y Edgar Mendoza

Repartimiento y conflictos en San Pedro Molinos, jurisdicción de Teposcolula, Oaxaca, fines del siglo XVIII

Dossier La vigencia del estudio de los repartimientos en época de subdelegados

que en Teposcolula, apenas se registraron dos. A partir del número de estos conflictos, se puede profundizar y contrastar las implicaciones que tuvieron las nuevas normas en las distintas subdelegaciones. Ello permitiría desentrañar el funcionamiento del sistema de repartimientos con base en las particularidades de su producción predominante para, posteriormente, realizar análisis comparativos que permitan sacar a la luz aquellos factores que facilitaron la continuidad o suspensión de esta práctica. Respecto a Villa Alta, Luis Alberto Arrioja se ha ocupado de estudiar los repartimientos en ese período y ha confirmado su continuidad en las primeras décadas del siglo XIX, como lo indicó Sánchez Silva. ${ }^{10}$ En nuestro caso, nos preguntamos ¿qué sucedió con este sistema en la jurisdicción de Teposcolula, en qué medida se cumplieron los preceptos legislativos, cuáles fueron las respuestas, conflictos, acuerdos y negociaciones entre los pueblos y los alcaldes mayores y sus tenientes que administraban el repartimiento?

A través del estudio de un litigio iniciado en marzo de 1787 y que finalizó al año siguiente, se tratará de responder estas interrogantes. El pleito en cuestión comenzó a partir de la denuncia presentada en la Audiencia de México por el regidor Juan Diego García, común y naturales del pueblo de San Pedro Molinos, sujeto de la cabecera de San Mateo Peñasco, jurisdicción de Teposcolula, contra su alcalde mayor y sus tenientes sobre reparto de mulas, grana, panela, entre otros productos. ${ }^{11}$

Además de la utilización de documentación del Archivo Histórico de Notarías de Oaxaca y del Archivo General de la Nación de México para la reconstrucción de trayectorias de varios personajes, la fuente principal de este trabajo es un expediente que se encuentra en el Archivo Histórico Municipal de Oaxaca, en la sección de procesos judiciales. Este fondo está integrado por los expedientes judiciales a cargo de los distintos funcionarios de la ciudad de Antequera: alcaldes ordinarios, alcalde mayor, corregidor y, a partir de 1787, del intendente de Antequera. Es necesario precisar que el litigio y averiguación que nos ocupa, fue encargado inicialmente al juez Antonio de Gándara,

\footnotetext{
10 Arrioja, op cit, p. 125.

11 “Autos formados a pedimento del regidor, común y naturales del pueblo de San Pedro Molinos, sujeto de la cabecera de San Mateo Peñasco, jurisdicción de Teposcolula, contra su alcalde mayor y su teniente sobre reparto de mulas, grana, panela y demás”, 1787. Archivo Histórico Municipal de Oaxaca (en adelante AHMO), Corregidor, caja 5, 139 fojas.
} 


\section{AMERICANISTAS}

\section{ISSN 1988-7868}

\section{Huemac Escalona y Edgar Mendoza}

Repartimiento y conflictos en San Pedro Molinos, jurisdicción de Teposcolula, Oaxaca, fines del siglo XVIII Dossier La vigencia del estudio de los repartimientos en época de subdelegados

teniente general de la jurisdicción de Nochixtlán Peñoles. Esto se explica porque el propio alcalde mayor de Teposcolula y sus tenientes estaban involucrados en el proceso, por tanto, desde la Audiencia de México se comisionó al justicia más cercano para realizar las diligencias. En septiembre de 1787, la propia Audiencia delegó la resolución del caso al corregidor intendente de Oaxaca. Tal disposición significó el comienzo de la aplicación de la Ordenanza de intendentes en Oaxaca, coincidiendo con la llegada de Antonio Mora y Peysal, quien en su calidad de primer intendente tuvo la atribución de juez de segunda instancia respecto a aquellos casos que no resolvían los subdelegados o en los que éstos se encontraban involucrados y, por lo tanto, no estaban facultados para dirimirlos. ${ }^{12}$

La estructura del artículo se divide en cuatro apartados, en el primero se describe las condiciones socioeconómicas de la intendencia de Oaxaca, y en particular de la alcaldía mayor y subdelegación de Teposcolula; el segundo da cuenta de la situación política y las actividades productivas del pueblo sujeto de San Pedro Molinos y su cabecera San Mateo Peñasco; el tercero distingue algunos de los personajes que intervinieron en el litigio y otros actores. El cuarto, analiza la acusación que llevó a cabo la república de San Pedro Molinos contra el alcalde mayor y sus tenientes a la luz del proceso judicial y varios interrogatorios. Finalmente, en la conclusión se esbozan los intereses comerciales que estaban detrás de estas acusaciones.

\section{Oaxaca y Teposcolula a finales del siglo XVIII}

En la última década del siglo XVIII el coronel Carlos de Urrutia hizo una descripción de la intendencia de Oaxaca, formada en 1787 en gran parte de lo que era el obispado del mismo nombre e integrada por 20 subdelegaciones. En palabras de Urrutia, su capital, la ciudad de Antequera, estaba ubicada en el "dilatado y ameno" valle de Oaxaca, al pie de la sierra de San Felipe, "bañada en su circunferencia por los ríos Atoyac y Xalatlaco". Destacó que sus regulares edificios y rectas calles la hacían una ciudad hermosa con un clima templado y benigno, "de alegre cielo y buenas aguas". Ahí residía el intendente corregidor, el cabildo secular y las cajas de Real Hacienda con sus dos ministros. En ella existían las administraciones principales del tabaco, pulques, alcabalas,

12 José Luis Alcauter, Subdelegados y subdelegaciones. Gobierno Intermedio y territorio en las intendencias novohispana, Zamora: El Colegio de Michoacán, 2017, pp. 94 y 96. 


\section{AMERICANISTAS}

\section{ISSN 1988-7868}

\section{Huemac Escalona y Edgar Mendoza}

Repartimiento y conflictos en San Pedro Molinos, jurisdicción de Teposcolula, Oaxaca, fines del siglo XVIII Dossier La vigencia del estudio de los repartimientos en época de subdelegados

correos y lotería. También era lugar de asiento de la silla espiscopal "sufragánea de la de México", con su cabildo eclesiástico y respectivos tribunales. Contaba con dos hospitales y conventos de religiosos de Santo Domingo, San Francisco, San Agustín, La Merced, San Juan de Dios, Betlemitas, del Carmen y de religiosas de Concepción, Santa Catarina, Santa Mónica, Capuchinas españolas e indias, "cuyo número de los primeros asciende a 120 y de las segundas a 169". La población de la ciudad era de 19069 habitantes, mientras que la de los 64 pueblos que conformaban su distrito era de 37703 y en total sumaban 56 772 pobladores. ${ }^{13}$ Según el censo de Revillagigedo, en 1790 la población de la intendencia era de 411 336, dividida en 363080 indios, 25809 españoles y 21729 de otras castas. ${ }^{14}$ Ello indicaba que el $88 \%$ de la población de la provincia era india. Por su parte, en la jurisdicción de Teposcolula habitaban un total de 43591 individuos, de los cuáles 4388 eran españoles, 184 castas y 38974 indios. ${ }^{15}$ A ella pertenecían un total de 150 pueblos de indios (ver mapa), junto al distrito de Villa Alta y las Cuatro Villas del marquesado, eran las tres demarcaciones que agrupaban la mayor cantidad de localidades, más de cien cada una de ellas, de las más de novecientas que integraban intendencia de Oaxaca al final del siglo XVIII. ${ }^{16}$

Rodolfo Pastor señala que más del $80 \%$ de la población de Teposcolula era de indios comunes o macehuales. Con base a los registros decimales, indica que este grupo, estaba estratificado internamente de acuerdo a criterios socioeconómicos. Esta diferenciación económica del indio común se debía a dos prácticas ilegales, que se habían ido consolidado progresivamente: la acaparación de las tierras de común repartimiento y

\footnotetext{
13 Enrique Florescano e Isabel Gil (Comps.), Descripciones económicas general de Nueva España, 17841817, México: INAH-SEP, 1973), p. 117. La descripción del coronel Urrutia fue un encargo del virrey Juan Vicente de Güemes, conde de Revillagigedo, ante la falta de informes por parte de los subdelegados e intendentes, quiénes teóricamente debían aportar datos estadísticos, geográficos, entre otros, sobre sus jurisdicciones.

${ }^{14}$ Hugo Castro Aranda, Primer Censo de la Nueva España 1790. Censo de Revillagigedo "Un Censo Condenado”, México: INEGI/Sociedad Mexicana de Geografía y Estadística, 2010, pp. 35 y 207.

15 Ibidem, p. 207.

16 Florescano y Gil, op cit, p. 118; Luis Alberto Arrioja, "Pueblos divididos y nobles empobrecidos. Villa Alta (Oaxaca), 1750-1808”, en Yanna Yannakakis, Martina Schrader-Kniffki y Luis Alberto Arrioja, Los indios ante la justicia local. Intérpretes, oficiales y litigantes en Nueva España y Guatemala (siglos XVIXVIII), (México: El Colegio de Michoacán/Emory University, 2019), pp. 206-207. Para un panorama bastante detallado del contexto socioeconómico de finales del siglo XVIII en Oaxaca, véase Sánchez Silva, "El comercio indígena en Oaxaca entre colonia y república", en Boletín de fuentes. América Latina en la historia económica. Economía indígena, (12, Instituto Mora, 1999) , p. 81.
} 


\section{AMERICANISTAS}

\section{ISSN 1988-7868}

Huemac Escalona y Edgar Mendoza

Repartimiento y conflictos en San Pedro Molinos, jurisdicción de Teposcolula, Oaxaca, fines del siglo XVIII Dossier La vigencia del estudio de los repartimientos en época de subdelegados

la crianza individual de ganado por parte de los macehuales. Destacó que, a diferencia de los indios principales, cuyas actividades rentables eran la producción de pulque, el comercio y la ganadería, "los macehuales ricos siguen siendo predominantemente agricultores: siembran maíz y trigo, solo que en cantidades comerciales". Concluye que la mayor parte de los indios comunes ricos no tenían otra riqueza más que sus tierras. ${ }^{17}$

Siguiendo con el aspecto económico regional, la mayoría de las 20 jurisdicciones oaxaqueñas se dedicaban, entre otras actividades, a la cría de la grana cochinilla. El capital mercantil financiaba gran parte de la producción del tinte, el cual se convirtió en un artículo especialmente valioso entre 1770 y 1780, cuando su valor se elevó de 15 a más de 30 pesos por libra. En ese tiempo se llegaron a realizar transacciones a gran escala. Por ejemplo, entre 1781 y 1784 el alcalde mayor del distrito costero de Jicayán, distribuyó entre la población local 400000 pesos en efectivo. Los mestizos y mulatos cambiaban el algodón que producían por otras mercancías en las tiendas que el propio juez local mantenía, mientras que los indios de la provincia lo hacían por grana cochinilla. Siguiendo el circuito legal de comercio, el algodón y la grana eran enviados a Puebla, aunque el tinte continuaba su camino hasta Veracruz para su exportación. ${ }^{18}$ Para el transporte de estos productos se requería de gran cantidad de mulas y cueros para la elaboración de los zurrones, paquetes en los que se trasladaba la grana y solían contener nueve arrobas del tinte. Los propios alcaldes mayores se encargaron del abastecimiento de ganado. En 1785 el corregidor de Oaxaca, afirmó que en una ocasión había traído mil reses de Guatemala, en el camino habían muerto 150 y el resto las había "apacentado" dos meses antes de venderlas. Cada una le había costado 14 pesos y fueron vendidas en 18 pesos. Por su parte, el alcalde mayor de Zimatlán dijo haber adquirido mulas a 16 pesos que después vendió a 25 dando crédito por un año. ${ }^{19}$ Como se puede observar, el alcalde mayor era un comerciante o un agente mercantil. Muchos de ellos obtenían capital y abastecimiento de los grandes mercaderes de la ciudad de México o de Oaxaca. Estos tratos solían incluir el acuerdo de que el funcionario real nombrara al cajero de su

\footnotetext{
17 Pastor, Rodolfo, Campesinos, op cit, p. 155.

18 Atlántida Coll-Hurtado, “Oaxaca: geografía histórica de la Grana Cochinilla”, en Investigaciones Geográficas Boletín, 36, (1998), p. 76.

${ }^{19}$ David Brading, Mineros y comerciantes en el México Borbónico (1763-1810), México: Fondo de Cultura Económica, 2004, p. 78.
} 


\section{AMERICANISTAS}

ISSN 1988-7868

\section{Huemac Escalona y Edgar Mendoza \\ Repartimiento y conflictos en San Pedro Molinos, jurisdicción de Teposcolula, Oaxaca, fines del siglo XVIII \\ Dossier La vigencia del estudio de los repartimientos en época de subdelegados}

habilitador como su lugarteniente en los asuntos judiciales. De este modo la autoridad local era ejercida simultáneamente a la consecución de beneficios económicos. ${ }^{20}$

A pesar de su prohibición por las Leyes de Indias, el sistema de repartimientos se había practicado en Oaxaca desde finales del siglo XVI. Sin embargo, la intensidad del mismo se había incrementado a partir de 1751, año en que la Corona tácitamente había permitido su funcionamiento. ${ }^{21}$ Esta situación se pretendió cambiar con la entrada en vigor de la Ordenanza de intendentes de 1786, cuyo artículo 12 prohibió la actividad comercial a los subdelegados, funcionarios que sustituyeron a los alcaldes mayores. ${ }^{22} \mathrm{El}$ primer intendente de Oaxaca, Antonio Mora y Peysal, consideraba necesaria la aplicación de dicha normativa para mejorar la situación económica tanto de la Corona como de los vasallos indios. En consecuencia, al tomar posesión de su cargo en 1787 se informó de cómo había funcionado el sistema de repartimiento en su jurisdicción y, entre los años de 1790 y 1794, participó en un debate epistolar entre el virrey Revillagigedo, el subdelegado de Villa Alta Bernardino Bonavia y el comerciante Juan Bautista Echarri sobre la conveniencia de mantener o no su prohibición. ${ }^{23}$

La discusión entre estos personajes y otros que se fueron sumando en el transcurso de los años, en contra o a favor de los repartimientos, es abordada por Hamnett. Este autor ubica a los inidividuos que estaban insertos en distintos niveles de la sociedad de la época: desde los subdelegados y comerciantes locales, pasando por el virrey y otras autoridades superiores del virreinato, hasta llegar a los miembros del Consejo de Indias y al rey. En

\footnotetext{
20 Más detalles sobre la asociación entre comerciantes y alcaldes mayores para efectuar repartimientos de mercancías en Oaxaca, ver Brading, op cit, 140-141; Hamnett,op cit; Escalona, op cit, pp. $200-214$ y Sánchez Silva, "Indios y repartimientos", op cit, pp. 108-109.

21 Escalona,op cit, p. 176; Sanchez Silva, "Indios y repartimientos", op cit, p. 105, indica que el repartimiento inició en Nueva España a fines del siglo XVI, "a partir de la crisis del sistema colonial temprano, cuando el tributo en trabajo fue suprimido y, además, la drástica crisis demográfica que sufrió la población nativa, disminuyó las posibilidades de que los indios continuaran siendo los únicos abastecedores de la economía española".

22 Real ordenanza para el establecimiento e instrucción de intendentes de ejército y provincia en el reino de la Nueva España, 1786, México: UNAM, 1984.

23 Archivo General de la Nación de México (en adelante AGN), Subdelegados, vol. 35, exp. 5,fs. 28- 44, 183-227v y 239, 1789-1793. Arrioja trabajó con la misma fuente para su estudio sobre Villa Alta, "De La prohibición a la persistencia, al igual que Hamnett, Política y comercio, pp. 116-126. Al parecer, en el Archivo General de Indias (AGI), se encuentra otra copia de los informes que el intendente de Oaxaca envió al virrey respecto a la práctica de repartimientos: AGI, México, 1974. Esta referencia aparece en los trabajos de Sánchez Silva, "Indios y repartimiento", op cit y del mismo autor"Comercio indígena”, op cit, y también en el de Hamnett, op cit.
} 


\section{AMERICANISTAS}

ISSN 1988-7868

Huemac Escalona y Edgar Mendoza

Repartimiento y conflictos en San Pedro Molinos, jurisdicción de Teposcolula, Oaxaca, fines del siglo XVIII Dossier La vigencia del estudio de los repartimientos en época de subdelegados

esos años, que van de 1790 hasta 1803 se debatió acaloradamente la suspensión de la prohibición de los repartimientos, sin que esto llegara a ocurrir, puesto que en 1803 una Nueva Ordenanza de Intendentes se hizo pública. En ella se reafirmó la prohibición estricta de los repartimientos en su artículo $54 .{ }^{24}$

En su correspondencia con el virrey, el intendente Mora y Peysal aportó detalles del funcionamiento de dicho sistema en distintas regiones de Oaxaca. Indicó que a excepción de la jurisdicción de Huajuapan, donde los indios pagaban con el ganado de la matanza lo que les repartían, en todas las demás "uniformemente" el fruto a que dirigían todos los alcaldes mayores su mira, era la grana. Matizó que en Teposcolula también había interés en el ganado, en las cuatro Villas del Marquesado el trigo, mientras que en Xicayan y Teutila el algodón. En Villa Alta también era relevante el algodón y las mantas que labraban con él las indias. Destacó que "para girar en esta especie de comercio no había otra regla de proporción", en relación a las cantidades que se introducían, “que el mayor o menor fomento que los justicias encontraban, ya en los fondos que sacaban a rédito de las obras pías, o ya en los que podían facilitar los aviadores que llegaban a conseguir". 25

Una vez conseguido el caudal e invertido una gran parte "en toros, caballos, mulas y algunos otros efectos y manufacturas", todo era trasladado a los partidos. Ahí se repartían entre los indios "los referidos efectos, a supremos precios". Por ejemplo, "tenían establecido para los chivos, al tiempo de comprarlos, el de seis reales por cabeza, cuando su valor era de diez". Por otro lado, distribuían dinero para producir grana, daban a los indios 12 reales por cada libra de grana "cuyo corriente ascendía a dieciocho, diecinueve, y veinte" reales. Pagaban tres pesos por la carga de trigo, que después vendían a siete y aún a nueve; por cada arroba de algodón daban seis reales, "que en Puebla y otros lugares, se expendía a dos pesos; un [peso] por la manta o tela que siendo, como hacían que fuese, del mejor tejido el precio corriente de ella era el de diez reales". En caso de que el indio no entregara a tiempo estos productos por no haberlos cosechado o por cualquier otro

\footnotetext{
24 Hamnett, op cit, pp. 130-141.

25 AGN, Subdelegados, vol. 35, exp. 5, fs. 192-193 v. 1792.
} 


\section{ISSN 1988-7868}

Repartimiento y conflictos en San Pedro Molinos, jurisdicción de Teposcolula, Oaxaca, fines del siglo XVIII Dossier La vigencia del estudio de los repartimientos en época de subdelegados

motivo, se le exigía el pago por la cantidad al que serían vendidos y no por el monto tasado en el repartimiento. Para lograr lo anterior, los alcaldes mayores, según el intendente, se valían "de aquellos medios duros y crueles, que eran consiguientes a la superioridad que les daba el mando, de la facilidad con que adquirían caudal, y a la insaciable ansia con que procuraron acrecentarlo". ${ }^{26}$

\section{San Pedro Molinos, sujeto de San Mateo Peñasco}

Una mirada atenta a los registros documentales sobre la época, nos muestran un panorama que contrasta con la descripción idealizada de Urrutia sobre el territorio oaxaqueño referida anteriormente. En efecto, durante el último tercio del siglo XVIII, los pueblos de indios del obispado de Oaxaca padecieron epidemias de cólera y de viruela, además se enfrentaron a continuas crisis agrícolas ocasionados por sequías y heladas. ${ }^{27}$ Por si fuera poco, entre 1707 y 1767 los pueblos de indios de la Mixteca trastocaron su organización socioeconómica y política, cuando muchos pueblos sujetos lograron efectuar la composición de sus tierras. Al delimitar su territorio y obtener un título de propiedad intentaron separarse de su cabecera, lo que generó graves conflictos entre pueblos sujetos, cabeceras y cacicazgos. ${ }^{28}$ Esta tendencia continuó en los años siguientes, así tenemos noticias de que pueblos como Santa Catalina Yuxia, sujeto a la cabecera de San Mateo Peñasco, solicitó su separación de este último. ${ }^{29}$ No hay registros de un

\footnotetext{
26 AGN, Subdelegados, vol. 35, exp. 5, fs. 192-193 v. 1792.

27 Edgar Mendoza, Los bienes de comunidad y la defensa de tierras en la mixteca oaxaqueña: cohesión y autonomía del municipio de Santo Domingo Tepenene, 1856-1912, México: Senado de la República, 2004, p. 73, entre 1779 y 1782, varios pueblos de la Mixteca solicitaron la reducción del tributo por las sequías y malas cosechas. AGN, Tributos, vol. 1781, 48, f. 26; Luis Alberto Arrioja, Pueblos de indios y tierras comunales. Villa Alta, Oaxaca: 1742-1856, Zamora: Michoacán: El Colegio de Michoacán, 2011, p. 513. Hamnett, op cit, p. 17, indica que entre 1785 y 1787 se experimentó una fuerte hambruna en toda la Nueva España.

28 Edgar Mendoza, "Composiciones de tierras en la Mixteca y la formación del territorio comunal de cabeceras y sujetos, siglo XVIII”, en Manuel Hermann (Coord.), Configuraciones territoriales en la Mixteca. Vol. I. Estudios de historia y antropología, México: CIESAS, 2015, 255-281.

29 En 1793, el virrey Revillagigedo accedió a la petición de Santa Catarina Yuxia para separarse de San Mateo Peñasco. AGN, Indios, Vol. 67, exp. 320, fs. 401-401v. A finales de 1803, el cura de San Mateo Peñasco (en mixtecto Yuunuu) reportó que tenía diez pueblos sujetos a la cabecera (ver mapa): Santa María Magdalena (Yuta noo yya), San Agustín (Ñuhu sihi), San Antonio (Dzinicahua), San Pedro Alto (Yucucuiy), Santa María de la Natividad (Yodzojuhua), San Pedro Molinos (Nuhuquisi), Santa Catarina Mártir (Nuhu tiquaha), San Pablo (Tisaha), San Felipe (Tindacu) y Santa Catarina de Sena. Irene Huesca, Manuel Esparza y Luis Castañeda, Cuestionario de don Antonio Bergoza y Jordán, obispo de Antequera a los señores curas de la diócesis, II, Oaxaca: Archivo General del Estado de Oaxaca, 1984, p. 321.
} 


\section{AMERICANISTAS}

\section{ISSN 1988-7868}

Huemac Escalona y Edgar Mendoza

Repartimiento y conflictos en San Pedro Molinos, jurisdicción de Teposcolula, Oaxaca, fines del siglo XVIII Dossier La vigencia del estudio de los repartimientos en época de subdelegados

proceso similar respecto a San Pedro Molinos. Al finalizar el siglo XVIII, pertenecía al curato de San Mateo Peñasco, lo que no significó la ausencia de conflictos y competencias, tanto con la cabecera como entre sus propios miembros, ello indica las desigualdades y jerarquías sociales internas. Veamos cuál era la situación del pueblo que en 1787 puso una queja contra su alcalde mayor por abusos en los repartimientos. Cabe puntualizar que existen registros de acusaciones similares del mismo pueblo y de sus propios vecinos en 1740 y 1757, cuando también solicitaron ayuda para enfrentar lo que consideraban abusos del alcalde mayor y su teniente en la práctica del repartimiento de grana. ${ }^{30}$ Lo que manifiesta la experiencia legal y las formas de resistencia de San Pedro Molinos para enfrentar este tipo de conflictos.

Aunque no tenemos datos de la década de 1780 relativos a San Pedro Molinos, sí contamos con referencias, de unas décadas anteriores, del pueblo cabecera. A mediados del siglo XVIII, José Antonio de Villaseñor indicó que la provincia de Teposcolula estaba compuesta por 32 pueblos cabecera. San Mateo Peñasco era uno de ellos, el cual contaba con su iglesia y cura clérigo, situado al sur de la cabecera del distrito, a una distancia de cinco leguas. Un total de 600 familias habitaban los barrios y pueblos cortos sujetos a su doctrina, entre ellos se encontraba San Pedro Molinos. Sus pobladores se dedicaban al cultivo del trigo y la cría de grana cochinilla. ${ }^{31}$ Más adelante, a comienzos del siglo XIX, el cura de Peñasco, Joseph Antonio Capitán, ${ }^{32}$ informó al obispo de Oaxaca en 1803 que había un total de 4457 habitantes en los once pueblos que integraban su curato, de los cuales 482 vivían en la cabecera y 348 en San Pedro Molinos. Ninguna de las dos localidades era la más poblada de aquella jurisdicción religiosa. Santa María Magdalena era la población con mayor número de habitantes, 1096.

El cura relató que los pueblos de esa zona habían estado adscritos a Tlaxiaco, pero que un siglo antes San Mateo Peñasco intentó separarse de aquella jurisdicción y

\footnotetext{
30 AGN, Indios, Vol. 54 , exp. 362, 1740; y AGN, Indios, Vol. 59, exp. 24, 1757.

31 José Antonio Villaseñor y Sánchez, Theatro Americano, descripción general de los reinos y provincias de la Nueva España y sus jurisdicciones, México, Editora Nacional, 1952, 134.

32 La información proviene de la contestación que hizo el párroco a un cuestionario del obispo de Oaxaca, Antonio Bergoza y Jordán, ver Huesca, Esparza y Castañeda, op cit, pp. 321-327.
} 


\section{AMERICANISTAS}

\section{ISSN 1988-7868}

Huemac Escalona y Edgar Mendoza

Repartimiento y conflictos en San Pedro Molinos, jurisdicción de Teposcolula, Oaxaca, fines del siglo XVIII Dossier La vigencia del estudio de los repartimientos en época de subdelegados

convertirse en cabecera de su propio curato. ${ }^{33}$ A mediados del siglo XVIII los dominicos dejaron de administrar religiosamente el curato y éste pasó a manos del clero secular. Señaló que predominaba el idioma mixteco entre sus pobladores y muchos de ellos, incluyendo mujeres, ya entendían y hablaban el castellano. Relató que en ese momento había un cura y un vicario en la parroquia que, según su opinión, era suficiente "para el ministerio". Respecto a la economía local, indicó que las "frutas especiales no las hay pero sí muchas comunes". Enfatizó que solo ponían atención en un maguey de donde extraían una bebida embriagante. Por su parte, años más tarde -en la década de 1820-, José María Murguía y Galardi registró que San Pedro Molinos estaba conformado de labradores que cosechaban maíz, trigo y frijol. Las mujeres del pueblo tejían mantas de algodón para sus vestidos y los de su familia. También apuntó que se dedicaban a la ganadería, pues contabilizó un total de 102 vacas de vientre y 66 bueyes mansos, además de otros tantos toros cerreros, yeguas de vientre, caballos mansos, cerdos, cabras, chivos y mulas de carga. Sus habitantes sumaban $274 .{ }^{34}$ La población de la cabecera de San Mateo perteneciente al partido de Tlaxiaco, también era de labradores dedicados a la cosecha del maíz, el trigo, el frijol y algo de grana. Aunque en esa zona no se cultivaba algodón, las mujeres lo compraban, lo hilaban y lo tejían. En aquel entonces, Peñasco sumaba 307 habitantes y contaba igualmente con ganado de distintos tipos, pero en menor cantidad que San Pedro Molinos: 51 vacas de vientre y 48 bueyes mansos. Esta diferencia significaba que el pueblo sujeto tenía mejor situación económica que su cabecera, San Mateo Peñasco.

Sugerimos también que la riqueza de San Pedro Molinos se debió también a otro factor. Rodolfo Pastor señala que en este pueblo hubo molinos de trigo en el siglo XIX, "que existían desde el primer siglo colonial". ${ }^{35}$ Vicente Moctezuma y Andrea Calderón

\footnotetext{
33 Marta Martín, Territorialidad y paisaje a partir de los traslados y congregaciones de pueblos en la Mixteca, siglo XVI y comienzos del siglo XVII : Tlaxiaco y sus sujetos, México, CIESAS, 2018, p. 558, señala que San Mateo Peñasco "se erigió como parroquia en 1706, dejando así de depender de la de Tlaxiaco, y también aglutinó como visita a los pueblos circunvecinos".

34 José María Murguía y Galardi, Primera y segunda parte de la estadística del Estado libre de Oaxaca. Año de 1826, en Carlos Sánchez Silva y Luis Alberto Arrioja, Las Estadísticas Históricas Oaxaqueñas. De la crisis del orden colonial a la revolución mexicana, Oaxaca: UABJO/El Colegio de Michoacán / Gobierno del Estado de Oaxaca, 2012.

35 Pastor, Campesinos, op cit, 186.
} 


\section{AMERICANISTAS}

\section{ISSN 1988-7868}

Huemac Escalona y Edgar Mendoza

Repartimiento y conflictos en San Pedro Molinos, jurisdicción de Teposcolula, Oaxaca, fines del siglo XVIII Dossier La vigencia del estudio de los repartimientos en época de subdelegados

señalan que en San Pedro Tidaa y otros pueblos de los valles de Nochixtlán, Yanhuitlán, Teposcolula y Tamazulapan, donde la producción de trigo era abundante, se formaron molinos donde se trituraba el trigo para obtener harinas. ${ }^{36}$ Muchos de estos molinos estuvieron en manos de caciques y otros pertenecieron a la comunidad y cofradías de los pueblos de indios. La producción de harina se exportó a los mercados regionales como la ciudad de Oaxaca, la costa y la cañada, y los ingresos se destinaron para edificar templos religiosos y otras obras públicas. Sin duda que este hecho dejó huella en el nombre del pueblo conocido como San Pedro Molinos o San Pedro de los Molinos. ${ }^{37}$

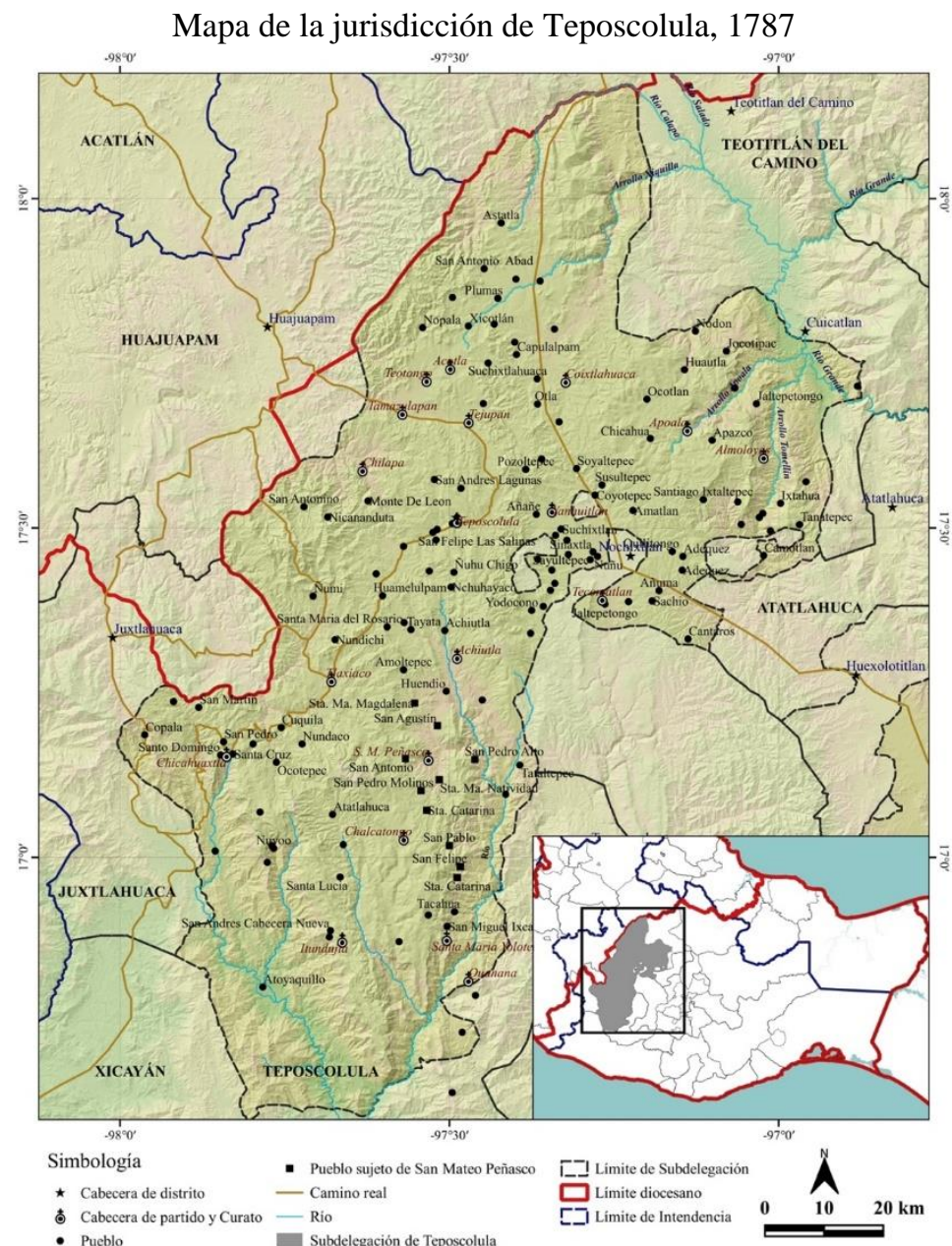

Mapa elaborado por Carlos Roberto Cruz Gómez

36 Vicente Moctezuma y Andrea Calderón, San Pedro Tidaá. Una vasta historia de la Mixteca Alta, México: Universidad Autónoma Metropolitana, Instituto Nacional de Antropología e Historia, 2009.

37 En su tesis doctoral Marta Martín, op cit, señala que está documentada la presencia de molinos hidráulicos desde el siglo XVII y que el control por los mismos suscitó pleitos entre San Pedro Molinos y sus pueblos vecinos. Marta Martín, , p. 65. 


\section{AMERICANISTAS}

ISSN 1988-7868

Huemac Escalona y Edgar Mendoza

Repartimiento y conflictos en San Pedro Molinos, jurisdicción de Teposcolula, Oaxaca, fines del siglo XVIII

Dossier La vigencia del estudio de los repartimientos en época de subdelegados

\section{Los personajes del litigio}

A lo largo del litigio intervinieron varios personajes de relevancia local y regional, a continuación presentamos una semblanza biográfica de aquellos actores sociales que dejaron sus huellas en los archivos. Comenzamos con el cura de San Mateo Peñasco, Joseph Antonio Capitán, originario de Tudela, Navarra. Dicho clérigo llegó a la Nueva España con la familia del obispo Buenaventura Blanco, quien ocupó la prelatura de Antequera entre 1754 y $1764 .{ }^{38}$ En su ciudad natal estudió gramática y moral, en Calatayud tres años de filosofía. Finalmente, en Oaxaca continuó estudiando moral hasta que fue enviado al curato de Pinotepa del Rey. En su respuesta al cuestionario que remitió en noviembre de 1803 al prelado Antonio Bergoza, apuntó que en ese tiempo contaba con 76 años, de los cuales llevaba 48 como párroco. Indicó que estuvo a cargo de la parroquia de Pinotepa del Rey y de su agregado de Cortijos, integrado por una importante población de alrededor de mil negros, mulatos y "otras castas avecindadas en aquella Costa del Sur". ${ }^{39}$ No precisó cuánto tiempo estuvo en Pinotepa del Rey, pero sí refirió que en Peñasco llevaba 38 años. De ahí podemos inferir que en 1765 llegó a la zona de la Mixteca, procedente de la Costa donde pasó 10 años y fue acusado por abusos en las transacciones mercantiles que realizó en aquel curato. En el pleito se le relaciona con un sobrino suyo llamado Manuel Capitán nacido en Navarra, España en 1750. A principios del siglo XIX, Manuel Capitán se registró como vecino de Antequera y comerciante. Entre 1803 y 1808 había sido regidor perpetuo y en 1806 alcalde de primer voto del cabildo de dicha ciudad. En 1808 había otorgado fianza para el subdelegado de Villa Alta, Ruiz Conejares. ${ }^{40}$

Continuamos con Pedro de Quevedo, alcalde mayor de Teposcolula durante el pleito, quien fue nombrado justicia mayor interino en 1783 por el virrey Matías de Galvéz. Posteriormente, el 18 de abril de 1784, recibió el oficio de alcalde mayor de esa

\footnotetext{
38 Eutimio Pérez, Recuerdos históricos del episcopado oaxaqueño, Oaxaca, Imprenta de Lorenzo San German, 1888, p. 48.

39 Huesca, Esparza y Castañeda, op cit, p. 326.

40 Silke Hensel, El desarrollo del federalismo en México. La élite política de Oaxaca entre ciudad, región y estado nacional, 1786-1835, Oaxaca: UABJO/El Colegio de San Luis/El Colegio de Michoacán, 2012, pp. 365-366.
} 


\section{AMERICANISTAS}

\section{ISSN 1988-7868}

Huemac Escalona y Edgar Mendoza

Repartimiento y conflictos en San Pedro Molinos, jurisdicción de Teposcolula, Oaxaca, fines del siglo XVIII Dossier La vigencia del estudio de los repartimientos en época de subdelegados

jurisdicción. ${ }^{41}$ Antes de pasar a Nueva España había seguido la carrera militar alcanzando el grado de capitán de infantería de los reales ejércitos. En abril de 1791 contrajo matrimonio con Mariana de Mendivil González. Quevedo fue el último alcalde mayor y el primer subdelegado de Teposcolula, siendo propuesto para dicho oficio por el intendente Mora y Peysal en 1788, en octubre de 1790 accedió a dicho cargo. ${ }^{42}$ Hamnett señala que su salario como subdelegado ascendió a un total de 1201 pesos, de los cuales 826 pesos eran producto del $5 \%$ de la recaudación tributaria y 375 pesos de la administración de justicia. ${ }^{43}$ En 1785 se le otorgó una licencia para matar 499 cabras y ovejas viejas en Teposcolula. ${ }^{44}$ Quevedo participó en el lucrativo negocio de la matanza de chivos, y al mismo tiempo practicó el repartimiento de mercancías desde el primer año que fue alcalde mayor, hay registros de su asociación con Francisco Martí, alcalde mayor de Villa Alta, para efectuar esta práctica. ${ }^{45}$ Según Hamnett, Pedro de Quevedo reportó, a manera de queja, la existencia de comerciantes residentes en Teposcolula y Tlaxiaco, así como de la presencia de mercaderes provenientes de Oaxaca. No cabe duda que esta competencia afectaba sus ganancias en los repartimientos. ${ }^{46}$ Rodolfo Pastor muestra que como subdelegado continuó con esa práctica a pesar de su prohibición. No obstante, también ejecutó órdenes del intendente en contra del subdelegado de Teozacoalco, "por su desobediencia y por usar indebidamente los fondos de los pueblos de su partido para su comercio ilegal". ${ }^{47}$ Es decir, al mismo tiempo que practicaba el comercio "ilícito", llevaba a cabo acciones para combatirlo en las jurisdicciones vecinas.

Los tenientes de partido eran una parte fundamental para el control de los distintos territorios que conformaban dilatadas jurisdicciones, como la alcaldía mayor y

\footnotetext{
${ }^{41}$ AGN, Reales Cédulas Originales, Vol. 228, exp. 43, f. 1; y Vol. 128, exp. 73, f. 3, 1784; Archivo General de Simancas (en adelante AGS), SGU,LEG,6960,21, 1783-1794.

42 AGN, Subdelegados, vol. 51, f. 264.

43 Hamnett, Política, 106.

44 AGN, General de Parte, Vol. 69, exp. 164, 1785.

45 AGN, TSJ Colonial, caja 335, exp. 93, 1791; AGS, SGU,LEG,6960,21, 1783-1794. En 1784 Quevedo presentó una solicitud al rey para la ratificación de su cargo en Teposcolula a raíz de la noticia del otorgamiento de la jurisdicción a otro solicitante, Francisco Carrillo. En dicha carta Quevedo expresó que ya había repartido grana y trigos entre los indios y hecho mucha inversión en su viaje a Nueva España. Refirió que entre 1783 y 1784 habían caído varias heladas que destruyeron las cosechas.

${ }^{46}$ Hamnett, op cit, p. 88.

47 Pastor, Campesinos, op cit, p. 150.
} 


\section{ISSN 1988-7868}

Repartimiento y conflictos en San Pedro Molinos, jurisdicción de Teposcolula, Oaxaca, fines del siglo XVIII Dossier La vigencia del estudio de los repartimientos en época de subdelegados

subdelegación de Teposcolula. En el esquema del repartimiento los tenientes de partido jugaban un papel relevante como lo ha demostrado Pastor y Sánchez Silva. ${ }^{48}$ Pedro Carrasquedo era teniente de Chalcatongo y Manuel Puerta de Achiutla, quienes fueron acusados junto al alcalde mayor de "excesos" en el repartimiento. Respecto a Manuel Puerta no tenemos más datos, pero sobre Pedro Carrasquedo existe mayor información. En 1784 estaba registrado como vecino de Villa Alta, ${ }^{49}$ es muy probable que de esa jurisdicción se trasladara a Teposcolula cuando Pedro Quevedo entró como alcalde mayor de ese distrito. Recordemos que el alcalde mayor de Villa Alta en ese año era Franciso Martí, quien estaba asociado con Quevedo en la práctica de repartimientos. Durante el transcurso del pleito, Carrasquedo ocupaba el cargo de teniente en Chalcatongo donde estableció su residencia y todavía en la primera década de 1800 aparece como vecino y labrador de Chalcatongo, desde donde participó en diversos tratos ante el notario Joseph Álvarez. Así, por ejemplo, en 1804 aparece como fiador por la cantidad de $2000 \mathrm{mil}$ pesos en el préstamo otorgado a Juan Francisco Oliveros por la cantidad de 25 mil pesos. ${ }^{50}$ Posteriormente, en 1805, fue uno de los fiadores del subdelegado de Teposcolula. ${ }^{51}$ Pastor indica que Ignacio Carrasquedo, hermano de Pedro, había sido subdelegado de Teposcolula. Aunque no precisa el periodo de su cargo, intuimos que fue entre $1795 \mathrm{y}$ 1805. Los hermanos Carrasquedo fueron acusados en repetidas ocasiones por los abusos en los repartimientos que practicaron. ${ }^{52}$ Finalmente, referimos al teniente general de Nochixtlán y su agregado de Peñoles, Antonio de Gándara, nombrado por la Audiencia de México como juez comisionado para realizar las averiguaciones en el curato de San

\footnotetext{
48 Pastor, "El repartimiento", op cit,; Sánchez Silva, "Indios y repartimiento", op cit.

49 Archivo Histórico de Notarías (en adelante AHNO), José Alonso Romero, libro 453, f. 52, 1784.

50 AHNO, Joseph Álvarez, libro 78, f. 32v, 1804.

51 AHNO, Joseph Álvarez, libro 79, f. 133, 1805. Hamnett, Política y comercio, p. 253, indica que Pedro Carrasquedo era comerciante de Tlaxiaco, lo integró a la lista de personajes involucrados en el proceso de Consolidación de vales reales. Así indica que en 1808, Pedro Carrasquedo realizó varios pagos relacionados con préstamos otorgados por obras pías y capellanías.

52 AGN, General de Parte, Vol. 72, exp. 125, fs. 70-70v. 1790; AGN, General de Parte, Vol. 75, exp. 180, f. 165v. 1795; y Pastor, Campesinos, op cit, pp. 135-136. El 15 de noviembre de 1804, los principales del pueblo de San Miguel Grande, del partido de Chalcatongo, otorgaron poder a Juan María Cervantes para que a su nombre y representación continúe el negocio pendiente sobre repartimiento de Ignacio Carrasquedo y perjuicios en el cobro y recaudación, AHNO, Joseph Álvarez, libro 78, f. 167v, 1804.
} 


\section{AMERICANISTAS}

ISSN 1988-7868

Huemac Escalona y Edgar Mendoza

Repartimiento y conflictos en San Pedro Molinos, jurisdicción de Teposcolula, Oaxaca, fines del siglo XVIII

Dossier La vigencia del estudio de los repartimientos en época de subdelegados

Mateo Peñasco. El distrito de Nochixtlán se encontraba relativamente cerca de la zona de conflicto (ver mapa).

Otro de los personajes relevantes en el litigio es el denominado cacique de San Pedro Molinos, Félix Guzmán, del cual no tenemos mayores referencias que el de ser cacique de su pueblo. Siguiendo el dato del apellido Guzmán podríamos identificarlo con la genealogía del cacicazgo de Yanhuitlán. Pastor explica que los cacicazgos de la Mixteca sufrieron con la crisis agrícola y demográfica de 1738. Según este autor, tal situación provocó una crisis económica general que afectó profundamente a toda la población y quebró definitivamente a muchos caciques, “confundiéndose con la crisis institucional de los cacicazgos, un $60 \%$ de los cuales no sobrevivirán la primera mitad del siglo". ${ }^{53}$ Es posible que esa sea la razón de la falta de registros relativos al cacicazgo de San Pedro Molinos. Marta Martín refiere la existencia de un hijo de Félix Guzmán, de nombre Andrés Antonio de Guzmán y Velasco en $1798 .{ }^{54}$

\section{A ras de suelo: injusticia y reclamos por repartimiento}

La propia dinámica de créditos a plazo de los animales o artículos que los alcaldes mayores y comerciantes habían repartido en los pueblos antes de 1786, así como los cargos adquiridos más allá de ese año, prolongaron por más tiempo las deudas y los cobros de las inversiones realizadas por éstos. Esta situación agudizó los conflictos y también los acuerdos y negociaciones entre los indios y sus acreedores, tal como sucedió en algunos pueblos de la jurisdicción de Teposcolula.

En marzo de 1787, el regidor de San Pedro Molinos y su común mediante su apoderado en la ciudad de México, Manuel Domingo Chavero, se dirigieron al fiscal de la Real Hacienda. Señalaron que en los meses de mayo y julio de 1787, se había presentado una "grande enfermedad", en varios lugares de la Nueva España,

\footnotetext{
53 Pastor, Campesinos, op cit, p. 333.

54 Marta Martin mencionó este dato en una ponencia inédita titulada "Cuestiones municipales en un sector de la Mixteca Alta (Oaxaca) desde el análisis del proceso de la formación de la república de indios a mediados del siglo XVI hasta las composiciones de tierras en el siglo XVIII", que presentó en en el II Congreso Internacional de Derecho Municipal. Quincentenario del municipio mexicano, organizado por El Colegio Mexiquense, la Universidad de Guanajuato, el Instituto de Investigaciones Jurídicas de la UNAM, la Red de Investigadores en Gobiernos Mexicanos (IGLOM) y la Asociación de Empresarios e Industriales del Estado de México (AIDEM), Toluca de Lerdo, 10 de abril de 2019.
} 


\section{AMERICANISTAS}

ISSN 1988-7868

Huemac Escalona y Edgar Mendoza

Repartimiento y conflictos en San Pedro Molinos, jurisdicción de Teposcolula, Oaxaca, fines del siglo XVIII Dossier La vigencia del estudio de los repartimientos en época de subdelegados

imposibilitando a los naturales sembrar sus parcelas. Al no haber suficientes cosechas, los indios tenían problemas para cubrir su subsistencia familiar, por tanto, no podían pagar sus contribuciones ni las deudas de los animales, panela y granos que les habían habilitado los alcaldes mayores y sus tenientes. Para colmo, ese año las heladas acabaron con las milpas y los frijolares, "padeciendo necesidades y angustias". Sin embargo, pese a ese panorama desolador, los tenientes del alcalde mayor, Pedro Carrasquedo establecido en la cabecera de Chalcatongo, y Manuel Puerta, en San Miguel Achiutla, exigían el pago efectivo del importe de mulas, machos, grana, panela, trigo, maíz y frijol que se habían repartido en esos años de crisis.

Ante los agravios, el apoderado de San Pedro Molinos, apuntó que "mis partes no se excusan a pagar, siempre y cuando el pago fuese justo y equitativo, ya que, a diferencia de otras partes, aquí las mulas de dos años tenían un valor de 33 y 35 pesos." ${ }^{55}$ En su afán de salir de aquella deuda, los indios propusieron la devolución de las mulas, argumentando que ya estaban mansas y que las habían mantenido durante más de 14 meses. Pese a que los deudores habían dado la mitad o más del pago, algunos solicitaron la devolución de las bestias o que los esperaran hasta levantar sus cosechas. Sin embargo, el alcalde mayor no admitió ninguna de las peticiones y exigió que los indios cubrieran la deuda restante.

Algo peor sucedió con los deudores de grana, pues en el caso de no pagar, el alcalde los remitió a trabajar a los trapiches, tarea a la que no "estaban acostumbrados y sufren quebranto y salud". Resultado de ello fue que algunos deudores se habían escondido y otros más, que asistieron a los trapiches, distantes a 14 leguas y de temperaturas cálidas, regresaron enfermos. Por si fuera poco, tres fallecieron, debido "al mal sustento, desvelos y cuatro días de ida y vuelta que no se pagan hacen que sobrevengan aquellas mortandades, dejando huérfanos y en desamparo a muchas

55 “Autos formados a pedimento del regidor, común y naturales del pueblo de San Pedro Molinos, sujeto de la cabecera de San Mateo Peñasco, jurisdicción de Teposcolula, contra su alcalde mayor y su teniente sobre reparto de mulas, grana, panela y demás”, 1787. AHMO, Corregidor, caja 5, 139 fojas. Se advierte al lector que todas las citas posteriores provienen de este documento. 


\section{AMERICANISTAS}

ISSN 1988-7868

Huemac Escalona y Edgar Mendoza

Repartimiento y conflictos en San Pedro Molinos, jurisdicción de Teposcolula, Oaxaca, fines del siglo XVIII Dossier La vigencia del estudio de los repartimientos en época de subdelegados

familias". Agregó que dicho alcalde mayor era dueño del trapiche y el teniente de Chalcatongo su íntimo amigo.

Sobre la panela, se manifestó su precio excesivo y su carácter perjudicial, porque los indios la utilizaban para preparar una bebida llamada tepache, "de la que resultan la embriaguez, riñas, adulterios y demás”. Por estos motivos, solicitaron, que en lo sucesivo ya no se hiciera repartimiento de ese producto. El apoderado señaló que en la distribución de mulas, grana y panela, los tenientes eran astutos para convencer a los indios, pero al momento de cobrar eran exigentes, y lo peor de todo eran sus excesivas ganancias. Por ejemplo, por la arroba de grana que habían pagado a los indios en 37 pesos y cuatro reales, "al respecto de 12 reales libra", la vendieron 72 pesos en el puerto de Veracruz el año anterior, lo que comprueba la usura con que se manejaba el alcalde mayor como su teniente" ${ }^{56}$ Por si no fuera suficiente, aquellos morosos recibían castigos:

A todo esto se agrega que si no cumplen con la obligación de cerrar sus cuentas, golpean a los infelices indios, abofetean, pisan y azotan, los remiten a los trapiches y los meten a la cárcel de Chalcatongo. Así acaeció con el regidor del pueblo de Santa María Yosondua y con el de Santa Catarina Yuxia, llamado Francisco Hernández a quien después de tenerlo preso 12 días le dieron 25 azotes, y todo esto no por otro motivo que no llevar a los deudores con la cuenta.

Los malos procedimientos de los tenientes se manifestaron en la exigencia para cobrar y en los castigos que se imponía a los deudores, pero los pueblos no se quedaron pasivos. Ante los agravios del teniente los habitantes de Achiutla se organizaron para expulsar una noche a pedradas al teniente de ese partido. Una situación similar tuvo el de Chalcatongo, cuando éste conducía a la cárcel al alcalde de Yosondua debido a no haber presentado a los deudores de los repartos. Ello provocó el "amotinamiento" de las indias del pueblo. Según el apoderado, de no haber intervenido el cura de la localidad el teniente habría sido golpeado brutalmente. No obstante, el alcalde mayor en lugar de reprender a su dependiente, ordenó aprehender a las mujeres que habían participado en la confrontación para llevarlas a la cárcel de Teposcolula. Ante tales acciones, la república

56 Desde mediados del siglo XVIII la arroba de grana en el sistema de repartimientos en varias zonas productoras, se valoró, en promedio, en 37.5 pesos. Véase Escalona, op cit, p. 195. 


\section{AMERICANISTAS}

ISSN 1988-7868

Huemac Escalona y Edgar Mendoza

Repartimiento y conflictos en San Pedro Molinos, jurisdicción de Teposcolula, Oaxaca, fines del siglo XVIII Dossier La vigencia del estudio de los repartimientos en época de subdelegados

de San Pedro Molinos solicitó a la Audiencia un pronto y eficaz remedio para evitar los excesos del alcalde. Para entonces, los indios no habían terminado de cubrir el monto de 37 pesos 4 reales de repartimiento que debían pagar en un plazo de seis meses, de no cumplir debían cubrir la cantidada de 50 pesos o su equivalente en bienes.

El 15 de mayo de 1787, el fiscal de la Real Hacienda respondió a la petición de San Pedro Molinos comunicando al juez local que debía ajustarse al bando de 7 de octubre de 1784, promulgado según la Real Orden de 25 de diciembre de 1783. El fiscal protector de indios tuvo noticia de las acusaciones en contra del alcalde mayor y recomendó no reservar la causa para el juicio de residencia, sino primero, proceder a una averiguación por un juez competente. Se avisó de esta determinación tanto a los indios de San Pedro Molinos como al alcalde mayor Quevedo.

Días después, ese juez sería don Antonio de Gándara, teniente general de Nochixtlán, quien por orden de la Audiencia llevaría a cabo las diligencias. Al mismo tiempo, Eusebio Ventura Beleña, oidor en la Real Audiencia y Juzgado General de Naturales, ordenó se liberara sin excusa a los presos que estaban en la cárcel de Chalcatongo y Teposcolula, por no haber cumplido con el importe total del repartimiento. También mandó se le entregará al regidor electo la vara de justicia, que probablemente le había negado el alcalde mayor. El 20 de junio del mismo año, el juez Gándara notificó a don Pedro de Quevedo, sobre la exigencia de llevar a cabo un interrogatorio.

Según las primeras fojas del expediente hasta aquí tratados, el alcalde y sus tenientes parecían culpables de las acusaciones por el cobro excesivo y los injustos castigos que impusieron a los deudores. Sin embargo, cuando se abrió el proceso, se efectuaron las diligencias y el interrogatorio a los testigos, se descubren contradicciones que vislumbran otros intereses. Cabe señalar que las preguntas fueron planteadas por el juez comisionado, con ayuda del propio alcalde Quevedo. Por tanto, es notorio que muchas de ellas estaban orientadas a demostrar la inocencia de los funcionarios. Veamos el contenido y la respuesta de algunas de éstas. La primera se hizo de manera individual a todos los deudores de los tenientes Pedro Carrasquedo y Manuel Puerta. Asimismo se examinó a los miembros del cabildo de San Pedro Molinos, Santiago Yosondua, San Mateo Peñasco, para que dijeran si el alcalde mayor había tenido alguna queja formal y 


\section{AMERICANISTAS}

\section{ISSN 1988-7868}

Huemac Escalona y Edgar Mendoza

Repartimiento y conflictos en San Pedro Molinos, jurisdicción de Teposcolula, Oaxaca, fines del siglo XVIII Dossier La vigencia del estudio de los repartimientos en época de subdelegados

verificar las acusaciones en su contra. La respuesta de todos fue favorable para el alcalde mayor, es decir, reconocieron que éste no los había forzado a participar en los repartimientos. En el mismo sentido la tercera pregunta abundó en el carácter voluntario del repartimiento de mulas. Se insistió en la premura mostrada por los indios de la cabecera de Peñasco y de San Pedro Molinos por conseguir bestias, que inicialmente estaban destinadas para su venta en los pueblos de la montaña.

Otro cuestionamiento, que en sí mismo lleva una respuesta del referido alcalde, es la siguiente:

Qué por cuanto la partida de mulas introducido por mí en noviembre del año pasado de ochenta y cinco, no solamente fue de dos años sino de tres y para arriba, que llegaron aquí también [trabajadas] que causó admiración, y por ellas concurrieron muchos vecinos y hacenderos de esta cabecera, de Tlaxiaco y Yanhuitlán [...] y me compraron al contado y a muy corto plazo, don Francisco Mata, 60 cabezas, Don Clemente Ferrón 52, Mariano Azcarraga 30, [...], el cura de Itunduxia 10, varios arrieros de Tlaxiaco 200 y más para los curas de Chalcatongo, Tejupan y otros religiosos, todo sobre precio de 28 a 33 pesos [...] las otras las dirigí a los pueblos de la montaña en que se comprenden y por la separación y división la ejecutan los vaqueros antes de que siendo notorio digan.

Sin duda, esta pregunta cuyo planteamiento contenía la respuesta, refleja que el reparto de mulas fue una de las principales actividades que dejaba buenas ganancias a los funcionarios. Por ejemplo, el alcalde mayor Antonio de Neira que ejerció el cargo entre 1766 y 1777, al momento de morir, quedó registrado en su testamentaria que sus bienes sumaron la cantidad de 18600 pesos. Dentro de este caudal estaban las mulas que le quedaban, las que se tasaron en 1550 pesos, además de sus mercancías de repartimiento (huipiles, grana, cera, sebo, tasajo salado y pieles) valoradas en 12512 pesos. $^{57}$

El resultado del interrogatorio a más de 50 testigos, mermó la gravedad de las primeras acusaciones en contra del alcalde y sus tenientes, además revelaron a otros

57 Pastor, Campesinos, op cit, p. 272. 


\section{AMERICANISTAS}

ISSN 1988-7868

Huemac Escalona y Edgar Mendoza

Repartimiento y conflictos en San Pedro Molinos, jurisdicción de Teposcolula, Oaxaca, fines del siglo XVIII Dossier La vigencia del estudio de los repartimientos en época de subdelegados

involucrados y manifestaron detalles sobre el repartimiento de mercancías. Pero lo que más llama la atención es que los nuevos miembros del cabildo de San Pedro Molinos, culparon a su cacique don Felix Guzmán de promover la demanda en contra de los tenientes y el alcalde mayor en la Ciudad de México, además de enviar documentos falsos a otros pueblos. ¿Por qué cambió la dinámica de las acusaciones en contra del alcalde y sus tenientes? ¿Hubo negociaciones, sobornos, amenazas o testigos comprados? ¿Acaso Pedro de Quevedo no era un funcionario abusivo? ¿Qué papel jugó en la demanda el cura y el cacique?

Fueron muchas las preguntas y los testigos que participaron en el interrogatorio, pero por el momento baste las respuestas contradictorias de la parte acusadora. Por ejemplo, cuando se presentaron el regidor, alguacil, topil y principales de San Pedro Molinos, con su respectivo intérprete, dijeron que ya se habían dejado en libertad a los dos presos, Isidro García y Martín Ortiz por su deuda de dos mulas que ellos habían pedido, sin fuerza ni persuasión. En cuanto a la panela, señalaron que dicho producto no había sido objeto del repartimiento, sino que el cacique Felix Guzmán era quien tenía el control de su comercio dentro del pueblo. Y probablemente distribuía tepache y aguardiente en los pueblos

En las indagaciones se mencionaron a otros actores que también efectuaron repartos como el cura Joseph Antonio Capitán y su sobrino Manuel Capitán. Ambos fueron señalados como compradores de grana y ganado. Sobre el cura expresaron los testigos que no maltrataba a sus feligreses, pero ocupaba a los indios para cuidar su ganado, conducir carneros a Oaxaca y limpiar y cultivar sus nopaleras "y en todos los demás menesteres de tráfico y manejo de sus casas, paga por semana a real por día”. Apuntaron que dicho clérigo no estaba de acuerdo con los repartimientos del alcalde mayor. En otras palabras, el cura y su sobrino tenían intereses concretos en el reparto de dinero para comprar grana y ganado, y por ello desde el púlpito seguramente influía en sus feligreses para evitar que Pedro de Quevedo y sus tenientes aumentaran sus negocios en aquel cuarto.

Enseguida comparecieron los miembros del cabildo de Santiago Yosondua, quienes declararon no haber intervenido en la acusación de San Pedro Molinos. 


\section{AMERICANISTAS}

\section{ISSN 1988-7868}

Huemac Escalona y Edgar Mendoza

Repartimiento y conflictos en San Pedro Molinos, jurisdicción de Teposcolula, Oaxaca, fines del siglo XVIII Dossier La vigencia del estudio de los repartimientos en época de subdelegados

Afirmaron la existencia de repartimientos de grana, "algunas mulas" y trigo. Precisaron que Carrasquedo solía dar algo de panela, pero "no han tenido quimera ni agravio". Aunque reconocieron que el alcalde de su pueblo, Diego Sánchez, estuvo en la cárcel dos días por no remitir a los deudores, y por ese motivo su mujer y otras cinco indias se excedieron reclamando al teniente, "pero no pasó de una tontería". También expresaron que tres individuos habían ido a trabajar a los trapiches para pagar su cuenta, pero no fueron obligados. Dos ya habían regresado a su pueblo y uno permanecía trabajando en el trapiche, mientras que los otros tres deudores se habían fugado sin prisión ni persecución alguna. Este testimonio aparentemente desmintió una buena parte de las acusaciones vertidas por los de San Pedro Molinos contra Quevedo. En el mismo sentido declararon los miembros del cabildo de la cabecera de Chalcatongo y San Miguel el Grande. Éstos negaron su participación en la acusación que San Pedro Molinos hizo en contra del alcalde y dijeron que el repartimiento que hacía Carrasquedo era voluntario y que no habían recibido agravio, ni castigo alguno.

Para comprender el papel del cura en este enredo, citaremos el testimonio del escribano de la provincia de Yanhuitlán, Bernardo Francisco de Arteaga, de fecha de 11 de julio de 1787:

Oídas, a personas distinguidas que el cura de Peñasco Don Joseph Capitán en el tiempo que lleva de párroco ha acopiado crecidas partidas de grana de repartimientos, y compras que ha hecho a los naturales de los pueblos de su doctrina, enzurronandola, y remitiéndola al puerto de Veracruz, con órdenes para su venta, queriendo simular esta negociación por medio de su sobrino Don Manuel Capitán a quien le tiene confiado capital grueso de pesos, por cuyos comercios, y otros asuntos fue removido del curato de Pinotepa del Rey para la paz, y quietud de aquel vecindario a el del Peñasco, a donde condu[jo] un casco de hacienda de ganado mayor que distribuyó, y comerció en el. Que sobre el curso impetrado, por los indios de los Molinos, ante la superioridad indicando a dicho señor y sus dependientes, no admite duda en creer que sería a influjos de dicho padre cura, dirigiendo para el efecto a Félix Guzmán, por la general oposición que ha manifestado a dicho señor, y antecesores, y es de público, como así mismo 


\section{AMERICANISTAS}

ISSN 1988-7868

Huemac Escalona y Edgar Mendoza

Repartimiento y conflictos en San Pedro Molinos, jurisdicción de Teposcolula, Oaxaca, fines del siglo XVIII Dossier La vigencia del estudio de los repartimientos en época de subdelegados

lo es, y le consta, que el dicho Félix Guzmán supuso haberle dado poder los demás pueblos para ellos, y verificándose lo contrario de no haberse mezclado directa, ni indirectamente las repúblicas de dichos pueblos en el referido curso, en que a buena luz se viene en conocimiento haber precedido este movimiento de dicho padre cura.

El testimonio del escribano de la jurisdicción de Teposcolula, personaje asociado Pedro de Quevedo, es una acusación directa contra el cura y su sobrino de ser los instigadores del litigio iniciado por San Pedro Molinos. Además señala la intervención del cacique local, don Felix Guzmán, en contubernio con el referido cura.

Ante estas declaraciones que culpaban al cura, el cacique don Felix Guzmán apoyado por el escribano de San Pedro Molinos, hicieron circular un documento con la firma del comisionado Antonio de Gándara, en papel sellado, que resultó ser apócrifo. Dicho documento fue enviado a varios pueblos y contenía una citación de las autoridades para presentarse en Teposcolula. Los cabildos de los pueblos acudieron a la cabecera de distrito y en ese momento se descubrió la falsedad del mandamiento ante la sorpresa del alcalde mayor y el propio Gándara. A partir de este suceso se inició una nueva ronda de interrogatorios para descubrir al autor o autores de este escrito que fue denominado "mandamiento falso, convocativo y alborotador". En consecuencia declararon los integrantes de las repúblicas de los curatos de Chalcatongo, Peñasco y Achiutla. ${ }^{58}$ La mayoría de los testigos dijeron que habían recibido el falso mandamiento por conducto de los indios de San Pedro Molinos. Se descubrió que el documento había sido enviado por el escribano y el cacique Felix Guzmán. En el mes de agosto de ese mismo año, ambos personajes fueron citados a declarar. Don Felix Guzmán confesó que era el responsable de la acusación presentada en la ciudad de México, y el autor de aquel mandamiento falso que se había distribuido en varios pueblos, por tanto, fue encarcelado junto con el escribano de San Pedro Molinos.

58 En esta ocasión se citaron a los miembros de la república de Santa Catarina Ticua, San Juan Teita, Chalcatongo, San Miguel El Grande, Santiago Yosondua, San Pedro el Alto, San Miguel Achiutla y San Pedro Molinos. 


\section{AMERICANISTAS}

ISSN 1988-7868

Huemac Escalona y Edgar Mendoza

Repartimiento y conflictos en San Pedro Molinos, jurisdicción de Teposcolula, Oaxaca, fines del siglo XVIII Dossier La vigencia del estudio de los repartimientos en época de subdelegados

En este punto se cerró el proceso judicial en contra del alcalde mayor y sus tenientes. En marzo de 1788, finalizó formalmente la controversia cuando Antonio de Mora y Peysal revisó los expedientes del caso a solicitud de San Pedro Molinos. Con base en dichos documentos y otros escritos conciliatorios, el intendente ordenó que se concediera la libertad al cacique Felix Guzmán, advirtiéndole que se manejara "sin suscitar discordia entre los pueblos”. Una vez cerrado el caso, Pedro de Quevedo desplazó momentáneamente a sus competidores y siguió desempeñando su cargo. En 1790 fue nombrado primer subdelegado de Teposcolula, oficio que desempeñó hasta $1794 .{ }^{59}$ Durante todos estos años él y sus asociados continuaron con el repartimiento hasta principios del siglo XIX. ${ }^{60}$

\section{Conclusión}

El análisis del litigio se explica a la luz de los cambios políticos y crecimiento económico "acumulado y sostenido" en el obispado de Oaxaca a fines del siglo XVIII, ${ }^{61}$ periodo en el que se agudizó la lucha entre los principales acaparadores de la producción india que se extraía del sistema de repartimiento. Sin duda, el alcalde mayor y sus tenientes tenían el predominio por su posición política y un sólido apoyo financiero. Sin embargo, la Ordenanza de intendentes de 1786 y la prohibición del repartimiento para los alcaldes o nuevos subdelegados, significó una nueva oportunidad para otros comerciantes y competidores, entre los que figuraba el cura Joseph Antonio Capitán y su sobrino, así como los caciques y gobernadores de los pueblos que articulaban a los grandes comerciantes y las unidades domésticas de producción. Al igual que ha mostrado Arrioja para el caso de Villa Alta, ${ }^{62}$ podemos interpretar que estos actores sociales trataron de aprovechar la coyuntura de cambios administrativos y nuevas regulaciones para favorecer sus intereses. Ello explicaría la actuación del cura y del cacique como instigadores de la

\footnotetext{
59 Hamnett, op cit, p. 106.

60 AGN, General de parte, Vol. 75, exp. 15, 1794. Para que el administrador de alcabalas haga que Pedro Quevedo absuelva la deuda de pesos de Pedro Carrasquedo.

${ }^{61}$ Elías Trabulse, (Coord.), Fluctuaciones económicas en Oaxaca durante el siglo XVIII, México, El Colegio de México, 1979, pp. 35-36.

62 Arrioja, "De la prohibición a la persistencia”, op cit, p. 93.
} 


\section{AMERICANISTAS}

ISSN 1988-7868

Huemac Escalona y Edgar Mendoza

Repartimiento y conflictos en San Pedro Molinos, jurisdicción de Teposcolula, Oaxaca, fines del siglo XVIII Dossier La vigencia del estudio de los repartimientos en época de subdelegados

acusación en contra del alcalde mayor y sus asociados por abusos en los repartimientos, que buscaba debilitar la posición de Quevedo frente a la Audiencia y al recién nombrado intendente de Oaxaca. Pero dicha estrategia no resultó si tomamos en cuenta que Pedro de Quevedo, lejos de verse maniatado en el ejercicio de sus prácticas mercantiles o alejado de la jurisdicción, se afianzó al prolongar su estadía como primer subdelegado de Teposcolula y continuó con sus repartimientos de mercancías. Con ello no pretendemos establecer una tendencia sobre el resultado de la prohibición en toda la intendencia de Oaxaca, pero sí buscamos aportar elementos y datos concretos que abonen a comprender la complejidad y diversidad regional de aquellos procesos socioeconómicos que se intentaron modificar a partir de nuevas regulaciones.

Respecto a San Pedro Molinos destacamos que al momento de la denuncia contra el alcalde mayor, no consta que tuviese pleitos por tierras o linderos con otros pueblos, o que intentase separarse de su cabecera. Tampoco encontramos datos relativos a posibles conflictos con el cura o con el cacique. Lo más paradójico es que, ni las autoridades ni otros sectores de su población, mostraron desacuerdos profundos con los repartimientos. La inconformidad manifestada provenía de la situación de penuria causada por las crisis agrícolas entre 1785 y 1787, que se manifestaron en sequías, heladas y hambrunas, lo cual redujo las posibilidades de cubrir a tiempo los compromisos asumidos en los repartimientos del alcalde mayor. Por tanto, más que eludir deudas, lo que se buscó fue una negociación para poder cubrirlas en un plazo mayor. Creemos que esta situación fue aprovechada por el cacique de San Pedro Molinos, en alianza con el cura, para desplazar los intereses mercantiles del alcalde mayor. Ello reflejó una fuerte influencia de Félix Guzman en las decisiones del cabildo así como en las acciones que se tomaron en nombre de la república ante la Audiencia de México.

Gracias al análisis del litigio entre San Pedro Molinos y los funcionarios reales de la jurisdicción de Teposcolula, podemos afirmar que las distintas manifestaciones en torno al repartimiento de mercancías entre los pueblos sujetos a San Pedro Peñasco, fueron determinadas por varios factores: la importancia de los productos repartidos, las coyunturas políticas locales, el impacto de catástrofes naturales y las nuevas disposiciones administrativas. Estos aspectos se combinaron y provocaron la reacción de los 


\section{AMERICANISTAS}

ISSN 1988-7868

Huemac Escalona y Edgar Mendoza

Repartimiento y conflictos en San Pedro Molinos, jurisdicción de Teposcolula, Oaxaca, fines del siglo XVIII

Dossier La vigencia del estudio de los repartimientos en época de subdelegados

protagonistas de este sistema mercantil financiero. Al tratarse de una subdelegación de la intendencia de Oaxaca productora de ganado menor, grana, panela y trigo, dicho sistema presentaba un elevado grado de articulación entre los diferentes sectores de la población local que hacía difícil, a pesar de los esfuerzos del intendente Mora y Peysal, que se concretara la desaparición del mismo en un corto plazo. En este sentido, el caso abordado guarda muchas similitudes con lo ocurrido en Villa Alta, donde la producción de mantas de algodón y de grana cochinilla estaba muy enraizada y articulada a redes mercantiles que rebasaban el ámbito regional. Sin embargo, encontramos diferencias en cuanto a la frecuencia de la conflictividad. Como señalamos antes, en los años posteriores a la prohibición de los repartimientos las protestas relacionadas con dicho sistema son mucho más recurrentes en Villa Alta que en Teposcolula. Cabe preguntarse a qué se debió esta diferencia entre una zona y otra. Quizá puede explicarse por la influencia de ciertos aspectos. En el caso de Villa Alta, se percibe la desaparición de cacicazgos, una mayor fragmentación del poder local y la intensificación de la lucha por el territorio. Queda por averiguar cuáles fueron los elementos que determinaron una mayor negociación entre caciques, pueblos productores y funcionarios locales en Teposcolula que evitaron pleitos y litigios de mayor trascendencia.

El caso que hemos tratado aquí contribuye a comprender la particularidad del funcionamiento del repartimiento de mercancías en una de las jurisdicciones más extensas del obispado e intendencia de Oaxaca. Al mismo tiempo, muestra que para fines del siglo XVIII, no es posible establecer generalizaciones sobre el fundamento voluntario o coercitivo de dicho sistema productivo y comercial. La pervivencia de este mecanismo financiero en San Pedro Molinos, en el marco de la puesta en marcha de la Ordenanza de Intendentes, implicó un reacomodo de los intereses económicos y sociopolíticos a nivel local y regional que involucró a distintos actores sociales: el cacique, el cura, la república de indios, comerciantes de la ciudad de Oaxaca, el alcalde mayor y sus tenientes. Así, podemos decir que la negociación constante entre indios, comerciantes, curas y funcionarios locales para adecuarse a diversas coyunturas (administrativas, políticas o medioambientales) fue una característica del repartimiento de mercancías en San Pedro Molinos. 


\section{AMERICANISTAS}

ISSN 1988-7868

Huemac Escalona y Edgar Mendoza

Repartimiento y conflictos en San Pedro Molinos, jurisdicción de Teposcolula, Oaxaca, fines del siglo XVIII Dossier La vigencia del estudio de los repartimientos en época de subdelegados

Finalmente, destacamos el uso de fuentes judiciales y notariales, ${ }^{63}$ para profundizar en el estudio del funcionamiento del repartimiento de mercancías en cada una de las áreas donde el sistema fue un eje articulador de intereses políticos y económicos. En ellas se pueden encontrar datos contrastables sobre los protagonistas de los pleitos, sus trayectorias y vínculos locales, regionales y virreinales, que aportan un panorama del conjunto de relaciones y factores económicos. Consideramos que este enfoque metodológico que involucra distintas escalas puede coadyuvar a desentrañar la pervivencia de un mecanismo financiero, que integró prácticas coercitivas y de negociación permanente, según el valor de los productos y más allá de los cambios legislativos emanados de las reformas borbónicas y del naciente estado republicano.

\footnotetext{
63 Este planteamiento no es nuevo y ha sido aplicado por otros autores para aproximarse a la historia de los pueblos de indios en la época colonial, véase Yanna Yannakakis, Martina Schrader-Kniffki y Luis Alberto Arrioja, op cit; Chance, op cit; y William Taylor, Embriaguez, homicidio y rebelión en las poblaciones coloniales mexicanas, México: Fondo de Cultura Económica, 1987. Lo que proponemos es combinar el uso de los documentos judiciales con los registros notariales, para identificar los distintos niveles de interacciones que implicó el sistema de repartimientos en un momento coyuntural como fue el último tercio del siglo XVIII.
} 